\title{
PATRIMONIO, DERECHOS HUMANOS Y MEMORIA EN CHILE. LA CALIFICACIÓN DE LOS SITIOS DE MEMORIA COMO PATRIMONIO CULTURAL
}

\author{
HERITAGE, HUMAN RIGHTS AND MEMORY IN CHILE. RATING SITES AS CULTURAL MEMORY
}

\author{
LUIS ALEGRÍA² / NATALIA URIBE³ \\ Fecha de recepción: 72 de julia de 2014. \\ Fecha de aprobación: 18 de agasta de 2014.
}

\section{RESUMEN}

La emergencia de una nueva categoría de patrimonio vinculada a la experiencia de las sistemáticas y masivas violaciones de derechos humanos constituye una de las consecuencias insospechadas de la implementación de las estrategias del terrorismo de Estado en Chile. Estas marcas físicas de la última dictadura militar (1973-1990) han quedado expresadas en los calificativos de atrocidad u horror con los cuales se procesan y narran socialmente. Argumentamos que para que aquello fuera posible fue necesario que se dieran tres procesos claves. Primero, la constatación de la experiencia extrema que representó la política del exterminio nazi y su valor universal. Segundo, como un efecto directo de la anterior, la conformación de una cultura de los derechos humanos de carácter planetario y tercero, la ampliación de la concepción tradicional de patrimonio cultural. Solo con la conjunción de estos tres fenómenos es posible identificar hoy a los sitios de memoria como un conjunto de bienes patrimoniales..

\section{PALABRAS CLAVE}

Memoria, derechos humanos, patrimonio cultural.

\section{ABSTRACT}

The emergence of a new category of assets linked to the experience of the systematic and massive violations of human rights, is one of the unexpected consequences of the implementation of the strategy of state terrorism in Chile. These physical marks of the last military dictatorship (1973-1990), have been expressed in the descriptions of atrocity or horror with which recount process and socially, we argue that for that to be possible, it was necessary to make themselves three key processes. First, the finding of extreme experience representing Nazi extermination policy and universal value, two, as a direct effect of the above, the creation of a human rights culture of a planetary, and three, the expansion of the traditional conception of cultural heritage. Only the combination of these three phenomena, it is possible today to identify sites of memory as a set of assets.

\section{KEYWORDS}

Memory, human rights, cultural heritage.

1. Investigación en el marco del proyecto: Campos de prisioneros en Chile. Reconfiguración de los lugares y las subjetividades. Investigador Responsable: José Santos-Herceg. Fondecyt № 1140200.

2. Luis Alegría, profesor de Historia y Geografía, UMCE; magíster en Antropología y Desarrollo, Universidad de Chile y doctor en Estudios Americanos, Instituto de Estudios Avanzados - Universidad de Santiago de Chile. Académico Facultad de Estudios del Patrimonio Cultural, Universidad SEK Chile, docente Facultad de Educación, Universidad Diego Portales Chile y profesor visitante en el programa de Magíster en Arte y Patrimonio, Universidad de Concepción Chile. (alegria.luis@gmail.com).

3. Natalia Uribe, bachiller en Ciencias Sociales, Universidad Alberto Hurtado; licenciada en Ciencias Políticas y Relaciones Internacionales, Universidad Alberto Hurtado; diplomada en Patrimonio, Comunidad y Cultura Local, Universidad de Santiago de Chile. (natalia.uribe.c@ gmail.com). 
La idea de un patrimonio de los derechos humanos y de la memoria es, quizás, uno de los últimos giros significativos del campo patrimonial. En este artículo, se tratarán los conceptos de horror y la atrocidad como ejes de articulación para diferenciar la idea de un patrimonio distinto a los otros patrimonios conocidos; además, se tratarán como conceptos sinónimos, aunque en las definiciones más específicas presenten ciertas diferencias. Por ejemplo, en el diccionario de la Real Academia Española de la Lengua se definen horror (2014a) y atrocidad (2014a) como:

Atrocidad: crueldad grande, barbaridad (exceso, demasía), dicho o hecho muy necio o temerario, error o disparate grave, insulto, increpación de fuerte carácter ofensivo.

Horror: sentimiento intenso causado por algo terrible y espantoso. Aversión profunda hacia alguien o algo. Atrocidad, monstruosidad, enormidad. Cantidad muy grande.

La relevancia de plantearnos estos conceptos es porque dan cuenta de una situación especial de anormalidad, diferente a otras conocidas en otro momento. Por tanto, una primera constatación de la emergencia de un patrimonio singular, distinto a los otros conocidos es que son resultado de unas condiciones de excepcionalidad. Por ello, las referencias de atrocidad y horror que enmarcan esta reflexión. Nos interesa remarcar que nos referimos a un repertorio de bienes, ya sean materiales o inmateriales, que son connotados como patrimoniales en tanto testimonios de la violencia racionalizadora, del paradigma del Terrorismo de Estado.

Nos referimos a un patrimonio de los derechos humanos o de la memoria por sobre otras definiciones como la de patrimonios incómodos (Prats, 2005), referidos a museos militares, $u$ otros repertorios patrimoniales políticamente incorrectos o actualmente indeseables, ya que creemos que el tratamiento de la memoria y el patrimonio incluso en los casos de situaciones de atrocidad, horror, violencia, muerte, termina siendo funcionalizado en el marco de discursos legitimadores de una acción política.

Parte de este fenómeno se expresa de manera más global en que:

A partir de las últimas décadas del siglo XX, el discurso del patrimonio y las políticas de preservación sufrieron importantes modificaciones. La categoría se amplió buscando reflejar la diversidad subyacente a la imagen homogénea que representaba a la nación. Es evidente que esta es una consecuencia directa de los movimientos poscolonialistas, de los nuevos nacionalismos, de los procesos migratorios y de un nuevo orden mundial denominado globalización. (Vasconcellos, 2013, p. 97).

\section{Emergencia de la cultura de la Memoria y los DDHH}

Inmediatamente después de finalizado el periodo nazi en Alemania, la mayor preocupación de las nuevas autoridades fue la creación de una cultura pública de la memoria, Es importante mencionar que dicha obra se realiza como una forma de constatar y visibilizar el horror que significó para el país y para el resto de los países de Europa la política belicista y de exterminio del nacionalsocialismo.

Los crímenes del holocausto judío ocupan la centralidad del recuerdo del nazismo (Faulenbach, 2010). Gran parte de la reflexión se enmarca en comprender las condiciones que hicieron posible dicha situación, los efectos sobre la población alemana en específico y general en la población europea de la segunda mitad del siglo XX. Casi fue el fin de la civilización. Lo que Adorno denominó con la frase "después de Auschwitz no se puede escribir poesía" y que continua con su tesis sobre la educación, "para que Auschwitz no se repita".

Que Auschwitz o Hiroshima se conviertan en la metáforas que condensan el horror ante la catástrofe causada por la violencia política en el siglo XX tiene que ver con la visibilidad que en la Segunda Guerra Mundial adquiere la dimensión racionalizada y estatalmente regulada del ejercicio de la violencia, estrechamente ligada al progreso de la técnica militar y de los dispositivos científicos de regulación biológica. (Peris, 2005, p. 56).

Comprender la masacre de poblaciones indefensas, la transgresión de las barreras de la civilización que significó el asesinato de niños, mujeres y ancianos no puede hacerse sino nos lo explicamos por un odio cuya excepcional intensidad abreva en una profunda acumulación de prejuicios (Burrin, 2004). Pero esto incluso es insuficiente, planteará el propio autor. Es clave mencionar que no era la primera vez que se producían masacres contra población indefensa y, por cierto, no fue la última situación que fue fácil de experimentar después de 1945, tanto en América Latina, África y Asia, y a finales del siglo XX en la propia Europa.

¿Pero qué hace distintas estas masacres con otras perpetradas en otros momentos y lugares?, especialmente las anteriores a los años de 1939 y 1945. 
¿Cómo explicar tanto odio y tanta violencia? En este momento, se llega a los límites de toda explicación racional, pues el esclarecimiento del horror nazi implica argumentar a favor de la comprensión de ciertos fenómenos que son complejos de representar e interpretar. Sin embargo, Durrin abordará la posibilidad de una explicación a partir de dos elementos centrales que pueden argumentarse a favor de una comprensión no simplista centrada en un solo personaje malévolo, sino en la persistencia de un antijudaísmo de larga data y la configuración de los términos técnico-racionales de la constitución del Estado moderno.

En apoyo de este enfoque, es válido destacar el enorme trabajo administrativo que acompañó toda la política de persecución del Tercer Reich. Su temible eficacia, sin duda, permite sostener que el racismo nazi era una tecnología altamente moderna y que el genocidio de los judíos fue una empresa muy diferente del genocidio de los tutsis en Ruanda. (Burrin, 2004, pp. 10-11).

Una cultura pública de la memoria se expresó en Alemania de manera inmediata al calor del proceso de pacificación y desnazificación del país, lo que incluyó tanto a las nuevas autoridades alemanas del post nacionalsocialismo como a los gobiernos de los países aliados triunfadores de la contienda mundial. Las primeras acciones consistieron en identificar y dimensionar los crímenes del nazismo. Así, se destacan los filmes y grabaciones de los horrores de los campos de concentración (Forges, 2006) y las visitas obligadas que realizaron a los campos de concentración los vecinos alemanes. Esta experiencia en directo, suerte de terapia de shock o pedagogía del horror, fue una política de adjudicación de la responsabilidad colectiva por dichos crímenes para toda la sociedad alemana, una carga que marcará durante un largo periodo a las nuevas generaciones.

Este procesamiento público de la memoria alemana se ha centrado en las víctimas del nazismo y su política se expresa en actos conmemorativos como los del 27 de enero y del 9 de noviembre 27 de enero. El primero de estos días representa el aniversario de la liberación de los campos de exterminio nazis. La ONU lo declarará como Día Internacional del Holocausto y el segundo, el Día Internacional contra el Fascismo y el Antisemitismo; a estos días conmemorativos se suman una gran cantidad de memoriales y sitios conmemorativos, de entre los que se destacan los ex campos de concentración, lugares auténticos, testimonios materiales y monumentos. Sin embargo, este proceso no estuvo exento de problemas, ya que la tendencia fue generar una dinámica de amnesia histórica, que permitiera superar el pasado nazi, pues el hecho que el nazismo y fascismo fueran derrotados desde el exterior impacto fuertemente en la sociedad alemana. Para Santacana y Hernández, "el proceso de desnazificación fue un éxito incontestable; hoy en día la sociedad alemana es una de las más avanzadas de Europa en cuanto a derechos sociales y liberalidad". (Santacana \& Hernández, 2006, p. 183). Pese a lo anterior, siempre quedan temas pendientes referidos a los procesos de memorialización y por tanto, de patrimonio, como por ejemplo la centralidad de las víctimas judías por sobre otros grupos sociales: homosexuales, gitanos para quienes su reconocimiento como víctimas fue bastante posterior y de alguna forma fue invisibilizado.

En ese marco, el desarrollo de una cultura pública de la memoria en Alemania, se ha ido constituyendo en un modelo de tratamiento del pasado. Es lo que Huyssen (2002) ha denominado "la mundialización del holocausto". Una de las preocupaciones centrales de todo los Estados, en toda época, ha sido la reflexión sobre cómo enfrentar el pasado traumático, legado de la vivencia de diversas formas de violencia experimentadas por las comunidades a lo largo de su historia como guerras mundiales, procesos de descolonización más o menos violentos, conflictos interétnicos al interior de contextos nacionales, experiencia de regímenes dictatoriales, violadores de derechos humanos, etc. (Venero y Toledo, 2009). En ese marco, las políticas y acciones de memoria en Alemania han sido un referente para países que sufrieron hechos traumáticos recientes.

[...] no cabe duda de que la promoción de espacios patrimoniales de instrucción y conocimiento del pasado ha ayudado también, y ayuda, a cicatrizar conflictos profundos. En este sentido la musealización de la guerra se convierte en un importante activo de la cultura de la paz (Santacana y Hernández, 2006, p. 182).

Estos elementos y la conjunción de ellos en la configuración de un sistema racional burocrático de la muerte, que tuvo como punto de culminación el lanzamiento de la bomba atómica sobre Hiroshima, representaron el peligro de extinción para la propia humanidad. Este contexto es el que explica la emergencia del discurso de la memoria, pero también la emergencia de una nueva categoría, configurada en práctica social, que es la cultura de los derechos humanos. 
Entonces, un segundo momento clave de lo que será un patrimonio de los derechos humanos y la memoria es la cultura universal de los derechos humanos, proceso iniciado con la creación de las Naciones Unidas y la posterior redacción y publicación de la Declaración Universal de Derechos Humanos (1948). Es la marca de inicio de lo que podríamos considerar una cultura planetaria de los derechos humanos. Terminada la guerra se establecieron dos tribunales: Nuremberg y Tokio para juzgar a quienes en el transcurso de la guerra habían cometido graves crímenes contra la humanidad. Este marco judicial y legal será el origen de un sistema internacional de protección a la personas (Schaulsohn, 2000).

La denominación de "crímenes contra la humanidad" y la noción de "genocidio" son importantes cuando se trata de sucesos desarrollados, ya sea en tiempos de guerra o de paz, que afectan a personas indefensas, exceden las órbitas locales y nacionales y afectan a toda la humanidad. Por eso, su carácter de imprescriptibles. La noción de genocidio implica una política de exterminio física o cultural contra un grupo humano por razones religiosas, raciales, étnicas, políticas y nacionales.

La corriente de resguardo de los derechos, entonces, sobrepasa los ámbitos judicial y legal, desde el cual se instala la noción de derechos humanos para lograr plataformas de concienciación y prevención de violaciones de derechos humanos. De esta forma, tanto en Naciones Unidas como en la Unesco la temática de la educación en derechos humanos (EDDHH) será una preocupación central para evitar todo negacionismo del holocausto y para difundir un programa de sensibilización y compromiso por el respeto de los derechos de todas las personas.

Esta preocupación por los derechos humanos contará con actores claves, que no son solo los Estados participantes de la guerra, sino también un creciente movimiento de víctimas. Sobre todo los sobrevivientes de los campos de concentración, pero también los familiares y amigos de los exterminados; todos conformarán un movimiento como nunca antes se había pensado. Ahora las víctimas, los derrotados, se constituían en un cuerpo que se reivindicaba como testimonios vivos del horror y rápidamente se convirtieron en los narradores de la memoria de los ausentes y también en testigos de sus propias desventuras en el paso por los campos de exterminio nazi.
Primo Levi, Agamben, Harendt, Lyotard, Semprún, entre otros, constituyen los ejemplos más notables de lo que se ha denominado la "era del testigo". Las personas que vivieron la prisión política hacen un ejercicio de memoria individual, que es compartido y potenciado en el colectivo. Se lo han propuesto como una acción necesaria a realizar, asumiendo como un deber el acopio, el registro y el relato. Esto, por requerimiento o como acción reivindicativa, se cumple en diversos formatos, haciendo honor a una suerte de pacto no escrito de los prisioneros y prisioneras de contar lo sucedido, pero sobre todo como un deber que posee todo sobreviviente para con los ausentes y la sociedad en su conjunto.

En América Latina, esta cultura de los derechos humanos posee unos orígenes marcados a fuego en la década de los setenta con la instalación de un conjunto de regímenes de facto que violan los derechos humanos de manera sistemática y que en su mayoría son gobiernos de Fuerzas Armadas o sostenidos por ellas, apoyados ideológicamente en la doctrina de seguridad nacional en un contexto de Guerra Fría. (Salvat, 2005).

Según Elizabeth Jelin (2003), será a partir de las preocupaciones políticas por la recuperación de las democracias de los nuevos movimientos sociales, por la emergencia del pensamiento sobre la ciudadanía y la constitución de una subjetividad ciudadana, abonadas por la práctica política de lucha de los movimientos de derechos humanos, que en definitiva se instala en la región el surgimiento de un nuevo marco interpretativo de la esfera pública y por tanto, de la relación entre Estado y sociedad, así como de los mecanismos y articulaciones entre el plano de las condiciones materiales, las institucionales, la subjetividad y el nivel simbólico-cultural.

La memoria y el olvido, la conmemoración y el recuerdo, se tornan cruciales cuando se vinculan a acontecimientos traumáticos de carácter político y a situaciones de represión y aniquilación, cuando se trata de profundas catástrofes sociales y situaciones de sufrimiento colectivo. En lo individual, la marca de lo traumático interviene de manera central en lo que el sujeto puede y no puede recordar, silenciar, olvidar o elaborar. En un sentido político, las "cuentas con el pasado". En términos de las responsabilidades, los reconocimientos y la justicia institucional, se combinan las urgencias éticas con las demandas sociales y morales. Las tensiones entre la urgencia de rememorar y recordar hechos dolorosos, más los huecos traumáticos y las heridas abiertas constituyen a la vez en tema de investigación [y 
debate público, pero también] en uno de los mayores obstáculos para su propio estudio (Jelin, 2003, s/p).

El tercer proceso, mencionado anteriormente, lo constituyen los cambios operados al interior del campo del patrimonio, ya que desde la década del sesenta, se comienza a cuestionar la noción clásica y tradicional de patrimonio para incorporar nuevas formas. Este debate político permitió como efectos de dicha discusión que se haya redundado en lo que podríamos denominar la democratización del patri- monio y su "giro social y participacionista". (García Canclini, 1993) al incorporar en sus categorías para puesta en valor y resguardo a otros bienes que tradicionalmente quedaban excluidos de ese parámetro, ya que los bienes caracterizados como patrimoniales provenían de la alta cultura o de la matriz homogénea de la identidad nacional.

Durante mucho tiempo en la historia del patrimonio, se contaba la musealización de campos de batallas, lugares de muerte, la construcción de memoriales e

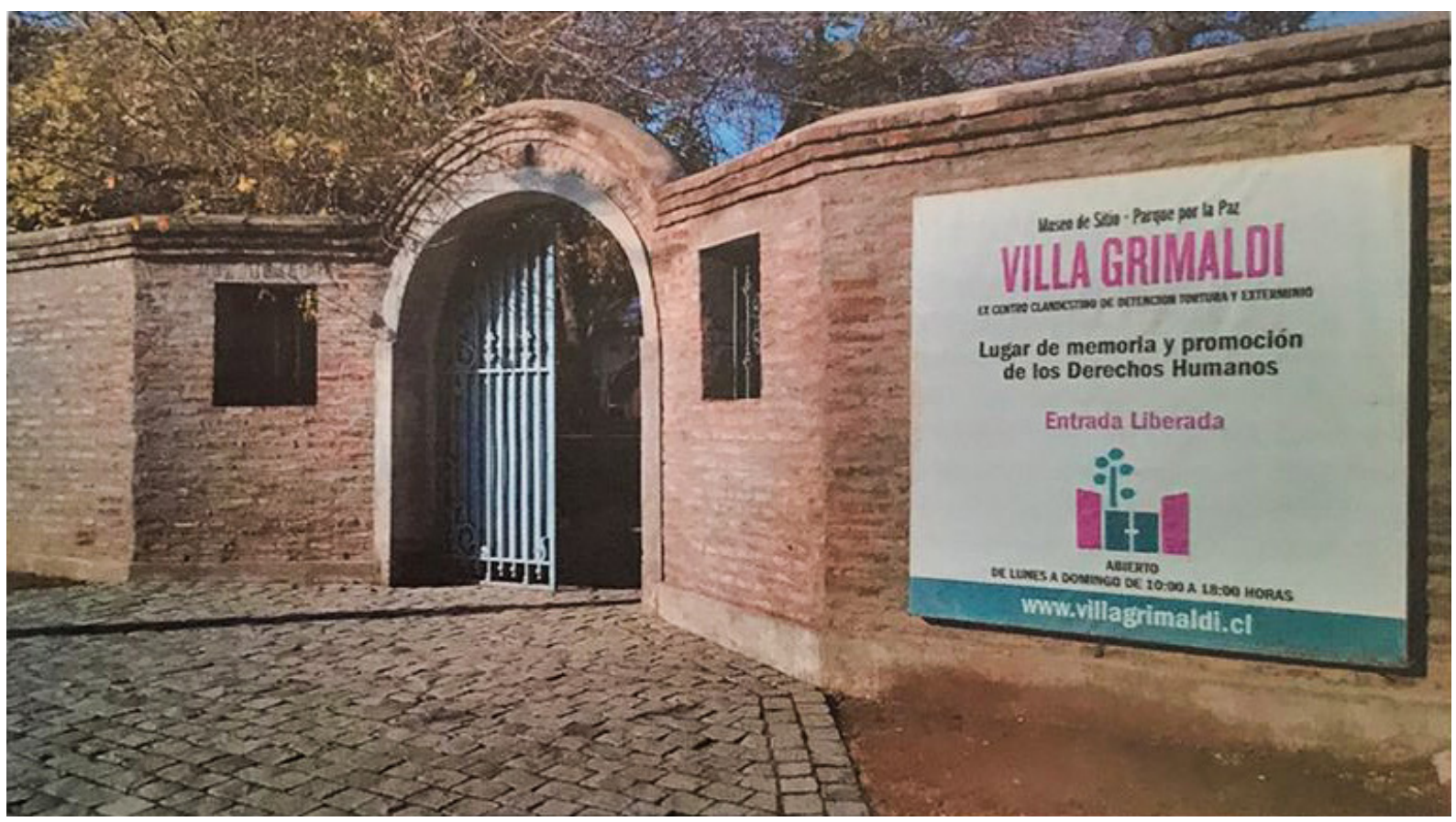

incluso monumentos a los caídos, pero casi en todos estos casos la acción de memorialización y patrimonialización fue llevada a cabo por los vencedores, especialmente Estados triunfadores e incluso perpetradores de violaciones de derechos humanos en pro de la gran causa nacional. El gran cambio opera con la concepción de una cultura de los derechos humanos que pone en el centro de los procesos de memorialización y patrimonio a las víctimas inocentes.

Se dirá que las víctimas han sido víctimas de la barbarie cuando no se pueda establecer lugares de memorias, cuando la bella obra conmemorativa fuese obscena, no sólo porque el acontecimiento fue terrible, sino porque ninguna superficie de inscripción puede recibirlo todavía. (Déotte, 1998, p. 241).
Figura 1. Parque por la Paz Villa Grimaldi.

Foto. Daniel Rebolledo 
Esto ha implicado el reconocimiento de variadas formas de patrimonio cultural, ya no solo como bienes tangibles de carácter monumental y/o exótico, como edificios, objetos de personalidades históricas (héroes), obras de arte o de folklore, etc., sino que hoy es posible identificar ejemplos de patrimonio inmaterial y/o popular que van nutriendo la agenda de lo patrimonial, con nuevos reconocimientos, institucionalidad y políticas de conservación y difusión.

En este contexto de discusión y revisión de la noción clásica de patrimonio, se comenzará a implementar toda una política de puesta en valor de los lugares marcados por las prácticas de exterminio como los ex campos de concentración, los lugares de violaciones de derechos humanos como la tortura o asesinatos en serie. Como lo explica una editorial de un número de la revista Museum Internacional:

Los lugares que fueron escenario de las guerras más feroces de la humanidad, de las playas de Normandía a los campos de concentración de Sachsenhausen y Auschwitz, pasando por la ciudad de Hiroshima, han sido transformados en museos del recuerdo y la reconciliación. Junto a ellos ha surgido una nueva generación de museos que presentan una dinámica de la paz a través del arte y ponen de manifiesto el poder de los artistas para despertar la conciencia pública en torno al concepto de paz. (Unesco, 1993, p. 3).

Es clave observar como en el caso de esta publicación todavía se continúa con cierta lógica de museo tradicional y se propone que tanto los museos de la guerra como los museos de la paz poseen como objetivos comunes contribuir a un mundo de paz y cultura de los derechos humanos sin manifestar mayor cuestionamiento a las complejidades particulares que se deben resolver al momento de implementar un museo de características particulares; tema que Déotte (1998) trata de abordar en su obra.

Sin embargo, en el artículo referido a Auschwitz, titulado: Auschwitz, el más extraño de los museos el vicepresidente del Consejo Internacional para la Creación del Museo de Auschwitz, plantea en el inicio:

Auschwitz ahora un museo, es también el cementerio más terrorífico del mundo. Sus colecciones -es decir todo lo que allí se encuentra, ya sean los edificios, muebles, objetos de uso cotidiano, las pertenencias personales e incluso la tierra- están impregnadas de las cenizas de los seres humanos que allí perecieron quemados. Es el museo del arte de la deshumanización y de la maestría del genocidio. Por ello su importancia rebasa con mucho la de un museo en el sentido tradicional del término. (Wilkanowicz, 1993, p. 32).
Este punto nos parece central en la conformación de un patrimonio de la atrocidad y el horror, pues como lo mencionábamos en las definiciones al inicio del texto, las nociones que prevalecen son exceso, barbaridad, crueldad, monstruosidad, espantoso; es decir, hablamos de condiciones en extremo graves. Siguiendo a Déotte, para los casos de graves sucesos de violaciones de derechos humanos como crímenes de lesa humanidad o genocidio, el museo tradicional se muestra estrecho.

La cuestión esencial de un museo que sería de los tachados -no de los que fueron vencidos políticamente y militarmente, ya que su derrota podría ser repetida en una narración, en una historia, sino de los que ningún juez podrá rendir justicia, ni siquiera Yaveh al cabo de un tiempo- es la de la repetición necesaria, de la escritura en un sentido fuerte. Y por lo tanto, de una museografía que no sería narrativa, porque lo que se plantea con el desfallecimiento de los testigos, por ejemplo, es la cuestión tanto del relato como de una cronología. (Déotte, 1998, pp. 205-206).

En el caso de la museología, Francisca Hernández nos plantea que los museos están llamados a conservar la memoria de aquellos acontecimientos sociales y políticos que han tenido lugar durante el siglo XX y que se han destacado por el auge de los regímenes totalitarios, la usurpación de los derechos humanos y la discriminación e incluso aniquilación de minorías étnicas. Se destacan algunos casos de museos de la memoria y/o el horror más emblemáticos, como por ejemplo, el Museo de la Masacre de Nanjing (Japón), el Holocaust Museum de los Estados Unidos, el Centro Educativo de sobre el Holocausto de Tokio y el Museo Lituano sobre las víctimas del genocidio, entre otros. (Hernández, 2006).

En el texto de Hernández (2006), se menciona de manera especial el caso de la Casa de Ana Frank, ya que este espacio museal surgido a partir de la experiencia de una niña judía se plantea una misión que busca demostrar que jamás debe darse la exclusión de las personas por ningún tipo de razón y además "su objetivo no es otro que reavivar la memoria para que no se olvide una de las mayores tragedias sufridas por parte de la humanidad y, en consecuencia, no se vuelva repetir nunca”. (Hernández, 2006, p. 243).

Otro ejemplo interesante de cómo se ha ido configurando un campo específico del patrimonio de la atrocidad es la lista del programa de Unesco de Patrimonio Mundial con las declaratorias de lugares caracterizados por su gran impacto sobre las violaciones de derechos humanos. Tales son los casos del 
Campo de concentración de Auschwitz de Polonia (1979), el Memorial de la Paz en Hiroshima (1996) y Robben Island en Sudáfrica (1999). En este sentido, se trataría de lugares que significan una lección para toda la humanidad sobre el horror y la atrocidad que los propios seres humanos son capaces de implementar.

En el marco del desarrollo de los procesos de memorialización que emerge de los últimos procesos de democratización en el planeta con un fuerte componente de la sociedad civil, se crea la Coalición de Sitios de Conciencia en el año 1999. Por sitios de conciencia, debe entenderse a sitios históricos que cumplen con los siguientes objetivos:

1. Interpretan la historia a través de sitios históricos.

2. Participan en programas que fomentan el diálogo sobre temas sociales apremiantes.

3. Promueven los valores democráticos y humanitarios como objetivo fundamental.

4. Brindan oportunidades para la participación colectiva en temas que se plantean en el sitio.

Recién en el año 2001, en el seno del Consejo Internacional de Museos, se creará el Comité Internacional para Museos en memoria de víctimas de crímenes públicos, Icmemo:

Los museos en memoria de las víctimas de crímenes públicos se dedican a la conmemoración de las víctimas de crímenes de Estado, de crímenes cometidos con el consentimiento de la sociedad o en nombre de motivos ideológicos. Estos museos se sitúan en el sitio donde fueron cometidos esos crímenes o en lugares elegidos por los supervivientes y pretenden dar a conocer los acontecimientos del pasado situándolos en un contexto histórico creando a la vez fuertes vínculos con el presente. (ICOM, 2010-2012).

Esta declaración es interesante, pues pone de relieve parte importante de las discusiones que en el campo académico se han dado por los complejos escenarios de exterminio, genocidio, terrorismos de Estado y crímenes de lesa humanidad. Por todo lo anterior, hoy es posible hablar con propiedad de un patrimonio de la atrocidad o del horror. Sin embargo, para que un hecho acontecido sea calificado de atrocidad debe cumplir con tres condiciones según Ashworth y Hartman. (2005)

Debe existir un victimario o perpetrador humano y una víctima también humana. Quedan excluidos desastres naturales y la crueldad en donde cualquiera de los dos actores sean animales.
El perpetrador tiene que haber actuado de manera deliberada y consciente y la víctima debe ser inocente y no haber contribuido a su propio sufrimiento. Esto quiere decir que las personas expuestas a situaciones extremas de violaciones de sus derechos humanos se encuentran siempre en condiciones de desventaja con respecto a sus captores, perseguidores o victimarios.

Debe revestir un inusual grado de seriedad, imposible de medir.

Además, estos espacios del horror poseen una serie de funciones que no necesariamente se dan en un museo tradicional. De esta forma, se reconoce un gran valor patrimonial de los vestigios, las huellas, las evidencias y los restos de la atrocidad cometida hacia un otro.

Se busca sacar a la luz un legado oscuro, evitar que sea olvidado; esa es la idea de verosimilitud de todo patrimonio de la atrocidad. Este patrimonio como ningún otro se entiende como una enseñanza para no repetir la situación de horror; es la consigna del Nunca Más. Además, se reconocen y se da centralidad a las figuras que muchas veces quedan al margen de la historia: sobre todo las víctimas, pero también los perpetradores y aquellos que presenciaron los sucesos. Lo que prevalece es la representación de una sociedad dañada en su conjunto, ya que la atrocidad no solo afecta la relación víctima/victimario, sino que de alguna manera todos somos involucrados. Esto es lo que en otro sentido buscaba el terrorismo de Estado y la política de exterminio. Por último, estos nuevos patrimonios son espacios donde las víctimas encuentran un lugar para "sanarse" y generar vínculos de solidaridad. Este reconocimiento de las víctimas cumple una función reparadora de aquellas personas dañadas producto de la tortura, los malos tratos, la humillación (Marsal, 2010).

También, en esta categoría es posible mencionar los museos de la resistencia: espacios museográficos de tipo monográfico y de alcance local. Francia e Italia son los únicos países que cuentan con una red densa de museos de este tipo. Estos museos poseen un importante carácter social, ya que en ellos han participado los propios integrantes de los movimientos de resistencia, como el caso del movimiento Partisano.

\section{Los lugares de memoria}

La emergencia de los lugares de memoria en el cono sur y en especial en nuestro país es tributaria del gran proceso de democratización vivido después de largos 
años del terrorismo de Estado y la conjunción de una serie de dinámicas articuladas desde las organizaciones de derechos humanos, ex sobrevivientes de la represión, así como de familiares y amigos de víctimas, en conjunto con organizaciones de la sociedad civil comprometidas con la defensa de los derechos humanos.

Las políticas públicas de memoria tendrán un punto clave con la creación de las Comisiones de la Verdad. Para el caso argentino, se destaca la creación de la Comisión Nacional de Detenidos Desaparecidos (1983); para el caso de Chile, son claves la Comisión de Verdad y Reconciliación (1990) y la Comisión sobre Prisión Política y Tortura (2003). Estas comisiones, más la movilización de las organizaciones de derechos humanos han hecho posible en Chile la emergencia de los denominados lugares de memoria; toda una nueva tipología de configuración de la trama urbana de las ciudades del país, especialmente de Santiago.

El creciente desarrollo de una cultura pública de las diversas formas de recuerdo vinculadas a las experiencias del periodo dictatorial generó lo que podría considerarse un espacio público de la memoria.

A este espacio concurren tanto las tipologías emblemáticas que propone Stern, citado por López (2009), representadas en relatos, acciones y sectores sociales específicos como otras que paulatinamente han ido reclamado un lugar en la estructuración por la interpretación legitima del pasado. (Lopez, 2009, p.150).

En este momento, el desarrollo de los denominados lugares de memoria en nuestro país no ha sido nada sencillo. Es clave considerar que durante algún tiempo estos espacios se desenvolvieron con escasa presencia del mundo de los museos y el patrimonio. Esto en parte desbordado por la gran dinámica movilizadora de los organismos activistas de derechos humanos que en su primera etapa está marcada por la consigna de lucha Por verdad y justicia, que progresivamente han devenido en un movimiento de memoria, en el que el lema será la disputa por el pasado y el reconocimiento histórico de las víctimas en torno a la recuperación y colonización del espacio público, hasta la fase actual de un incipiente y emergente discurso patrimonial por la conservación y resignificación de los espacios recuperados o de aquellos que han surgido como producto de la política pública de reparación simbólica. Como lo plantea
García Canclini, todo lo anterior no está exento de contradicciones y desafíos:

Cómo trabajar sobre la memoria en la actualidad, cómo documentar dramas históricos, qué puede significar para el arte, ahora encandilado por las instalaciones, un arte tan poco museificable o tan difícil de museificar. Los estudios culturales tienen atractivas oportunidades para repensar el patrimonio, la historia, la memoria y los olvidos, a fin de que las instituciones y las políticas culturales se renueven con algo más que con astucias publicitarias (García Canclini, 2005, p. 6).

En este sentido, el campo de las memorias constituye uno de los últimos desafíos de los museólogos y del campo del patrimonio en general.

\footnotetext{
Es curioso: estamos en una época de vasta reflexión sobre la memoria. Se vuelve a repensar el holocausto, las dictaduras del Cono Sur en América Latina, otros países están redescubriendo qué hacer con su pasado. De modo que es posible pronosticar que nos estamos acercando a un momento en que se va a re-flexionar el museo por la necesidad de tener una institución que canalice esta nueva visión sobre la memoria. En todo caso, será la prueba para ver si el museo todavía es necesario. (García Canclini, 2005, p. 6).
}

Pero de alguna forma los denominados lugares de memoria han desbordado con creces el ejercicio de las prácticas museológicas a tal punto que hoy nos encontramos con lo que hemos denominado patrimonio de la atrocidad $\mathrm{u}$ horror, del modelo europeo devenido del tratamiento del régimen nazi, pero que para el caso de las situaciones de los países del cono sur adquiere una serie de especificaciones y complejidades.

Los lugares de memoria pertenecen a dos reinos. Es lo que les confiere interés, pero también complejidad: "simples y ambiguos, naturales y artificiales, abiertos inmediatamente a la experiencia más sensible, y al mismo tiempo, fruto de la elaboración más abstracta" (Nora, 2009, p.32). Son lugares en tres sentidos, materiales, simbólicos y funcionales. Una unidad significativa de orden material o ideal en la cual la voluntad del hombre o el trabajo del tiempo hace un elemento simbólico de un grupo determinado. (Venero \& Toledo, 2009).

Considerando lo topográfico, estos lugares de memoria constituyen marcas en el espacio y también en el tiempo., Es una forma de gestionar el recuerdo de sucesos significativos en el caso de las violaciones de derechos humanos perpetradas por los agentes del 


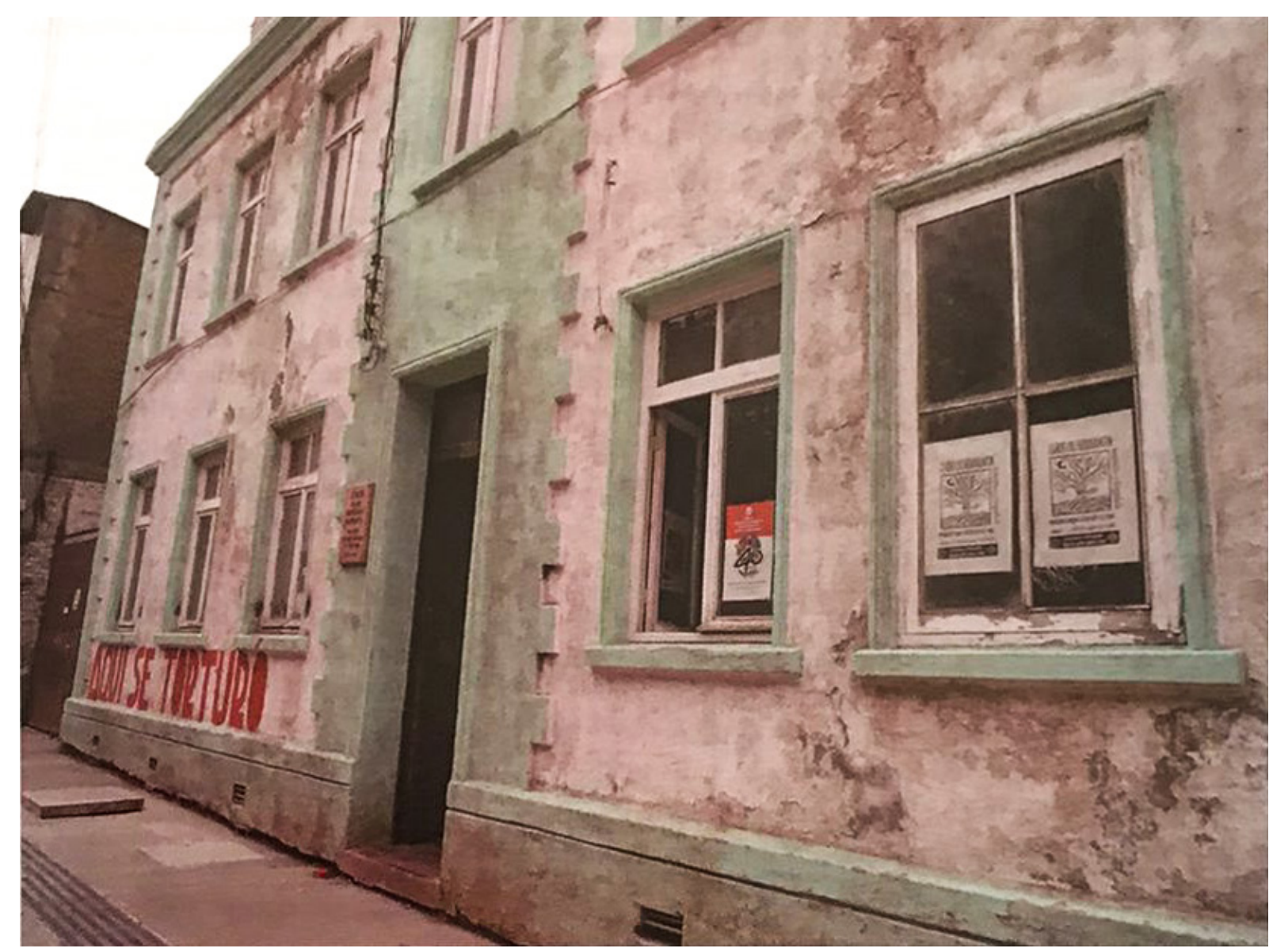

terrorismo de Estado que casi siempre son traumáticos.

Dadas estas características, los lugares de memoria pueden ser muy diversos, así como diversas las formas de abordarlos. Por ello, la necesidad de una tipología, para lo cual se abordarán tres niveles de clasificación. El primero, referido a su constitución como testimonios de la política represiva; el segundo, en torno a las acciones de invisibilización generadas tanto desde el régimen perpetrador como desde el modelo postdictatorial de transición y el tercero, en torno a las acciones de rescate y uso social de dichos espacios.

Un dato relevante para el caso chileno es que gran parte de estos espacios han sido declarados monumentos nacionales en su categoría de monumentos históricos, lo que implica el reconocimiento por parte del Estado de la trascendencia histórica de estos espacios como testimonios del horror dictatorial. Sin
Figura 2. Casa de los Derechos Humanos, Punta Arenas. Foto. Daniel Rebolledo 
embargo, es importante mencionar que en nuestro país, no ha surgido una discusión por una nueva categoría de patrimonio vinculada a la memoria y los derechos humanos, sino que más bien se ha adaptado la noción de monumento histórico como una medida para protegerlos de la destrucción. Pero es importante recalcar que esta categoría a su vez implica una gran responsabilidad para el Estado que les ha otorgado un estatus especial, lo cual debiera traducirse en el diseño de una política pública que se centre más en su desarrollo futuro y rol social, que simplemente en una medida de emergencia frente a la destrucción. Por otro lado, para quienes están en su gestión poseen una gran responsabilidad que implica velar por el resguardo del patrimonio de la memoria y los derechos humanos contenido en ellos, así como por su reconocimiento e inserción en la sociedad.

Siguiendo a López (2009), podemos encontrar:

Lugares secretos de detención y tortura: la mayor parte insertos en el funcionamiento normal de la ciudad. Los prisioneros permanecían completamente incomunicados y sometidos a interrogatorios bajo tortura, además de deplorables condiciones de subsistencia.

- Lugares de detención donde no se aplicaba tortura: lugares de espera o de tránsito, ya sea hacia otros recintos donde se realizaban interrogatorios y se aplicaban torturas.

- Campamentos de detenidos, también llamados campos de concentración, son creados a partir de 1973. Eran de conocimiento público y se permitía el contacto entre los prisioneros e incluso con sus visitas.

- Recintos de detención pertenecientes a instituciones: recintos de dependencia institucional de carácter público.

- Cárceles y penitenciarías: lugares de reclusión para prisioneros comunes, utilizados para encarcelar a presos políticos sometidos a procesos y condenas. En algunos casos, se practicó la tortura o la desaparición de algunos detenidos.

- Recintos para el funcionamiento interno de los servicios de seguridad: destinados a actividades administrativas, habitacionales y de entrenamiento de los agentes perpetradores.

En el caso de esta tipología, es clave mencionar, siguiendo a Fernández \& Piper (2011), que no todos los centros de detención y tortura consignados en las listas de los informes de nuestras comisiones de verdad son por sí mismos lugares de memoria, sino solo aquellos que son apropiados y utilizados, como dice Richard:

No basta con salvar de la destrucción a los vestigios del pasado condenable para activar el recuerdo, ya que éste depende siempre de una voluntad de memoria que intencione el acto de recordar en función de determinadas motivaciones sociales batallas políticas y urgencias críticas (Richard, 2010, p. 253).

Además de estos espacios, es posible mencionar las huellas en el espacio público en torno a sitios marcados, en especial sobre sucesos trágicos. De esta forma, se pueden mencionar memoriales, monumentos y placas recordatorias. En este caso, como resultado de la acción de la sociedad civil, como producto de las acciones de reparación simbólica del Estado o la suma de ambas iniciativas.

Parte importante de los lugares de memoria vinculadas a las violaciones de derechos humanos han sufrido acciones tendientes a borrarlos del espacio público. Silva \& Rojas (2005) plantean que estas acciones constituyen categorías posibles de identificar, tales como:

- Demolición. Se trata de una acción de destrucción del lugar. Caso de la casa José Domingo Cañas (centro secreto de detención y tortura).

- Ocultamiento. Cuando las actividades rutinarias u otras ocultan las acciones de represión. Estadio Nacional (centro secreto de detención y tortura).

- Apropiación y simulación. Se trata de una acción de disfrazar la identidad del sitio, por ejemplo con el cambio de numeración; caso de Londres 38 o Londres 40 (centro secreto de detención y tortura).

- Aislamiento. Se refiere a barreras geográficas o de accesibilidad que impiden el acceso al lugar físico. Caso Isla Dawson (Campo de concentración).

- Desconocimiento. Se refiere a lugares donde no se ha producido ningún registro de su uso como centro de detención y tortura. Caso Simón Bolívar (centro de exterminio que no dejó sobrevivientes).

Pero, además, las autoras Silva y Rojas (2005) han identificado las formas por las cuales los lugares de memoria se han recuperado y resignificado como sitios donde los sujetos vinculados biográficamente a ellos y quienes los visitan o recorren experimentan y generan una nueva relación entre el sitio (objeto) y los emprendedores/visitantes (sujetos). Estas formas son: 
Reproducción morbosa. Exhibición del horror. Bloqueo y distanciamiento.

Símbolo. Metaforiza el hecho. En el traspaso de la vivencia a una representación conceptual, pierde el significado.

Placa recordatoria. Transforma la memoria del hecho en un dato; se archiva como tal.

- Memorial. Tiene como única intención la conmemoración. Se recuerda el dato y se deja fuera la vivencia.

- Museificación. Objetualiza el hecho, le extrae lo singular, lo distancia y congela.

Finalmente, podemos agregar que independiente de las características de los sitios de memoria todos ellos en su calidad de tales:

Sintetizan el reconocimiento de lo sucedido en el pasado, la posibilidad de recordarlo en el presente, así como la de reflexionar y aprender respecto a éste en vías de construir futuros posibles... su análisis no sólo permite comprender el pasado que se recuerda, sino también el presente, que es el tiempo en el cual se realiza la memoria, y los escenarios que se prefiguran hacia el futuro desde aquellas marcaciones territoriales. (Fernández \& Piper, 2011, p. 35).

Dentro de las funciones básicas que cumpliría todo lugar de memoria, podemos enumerar un listado donde es posible apreciar ciertas funciones semejantes a las que desarrollan los museos en la actualidad. En la trilogía de investigar, conservar y difundir.

Histórica: recuperar la historia del sitio a través de la investigación y documentación tanto de su genealogía como espacio, así como de los sucesos acaecidos en el lugar. Esta función también implica el rescate y la puesta en valor de las memorias presentes en el lugar, así como el patrimonio tangible representado desde la arquitectura y los objetos materiales. También es clave la puesta en valor del patrimonio inmaterial representado en las prácticas y ritos sociales vinculados al sitio.

Figura 3. Sitio de Memoria 3 y 4 Álamos. Foto. Daniel Rebolledo

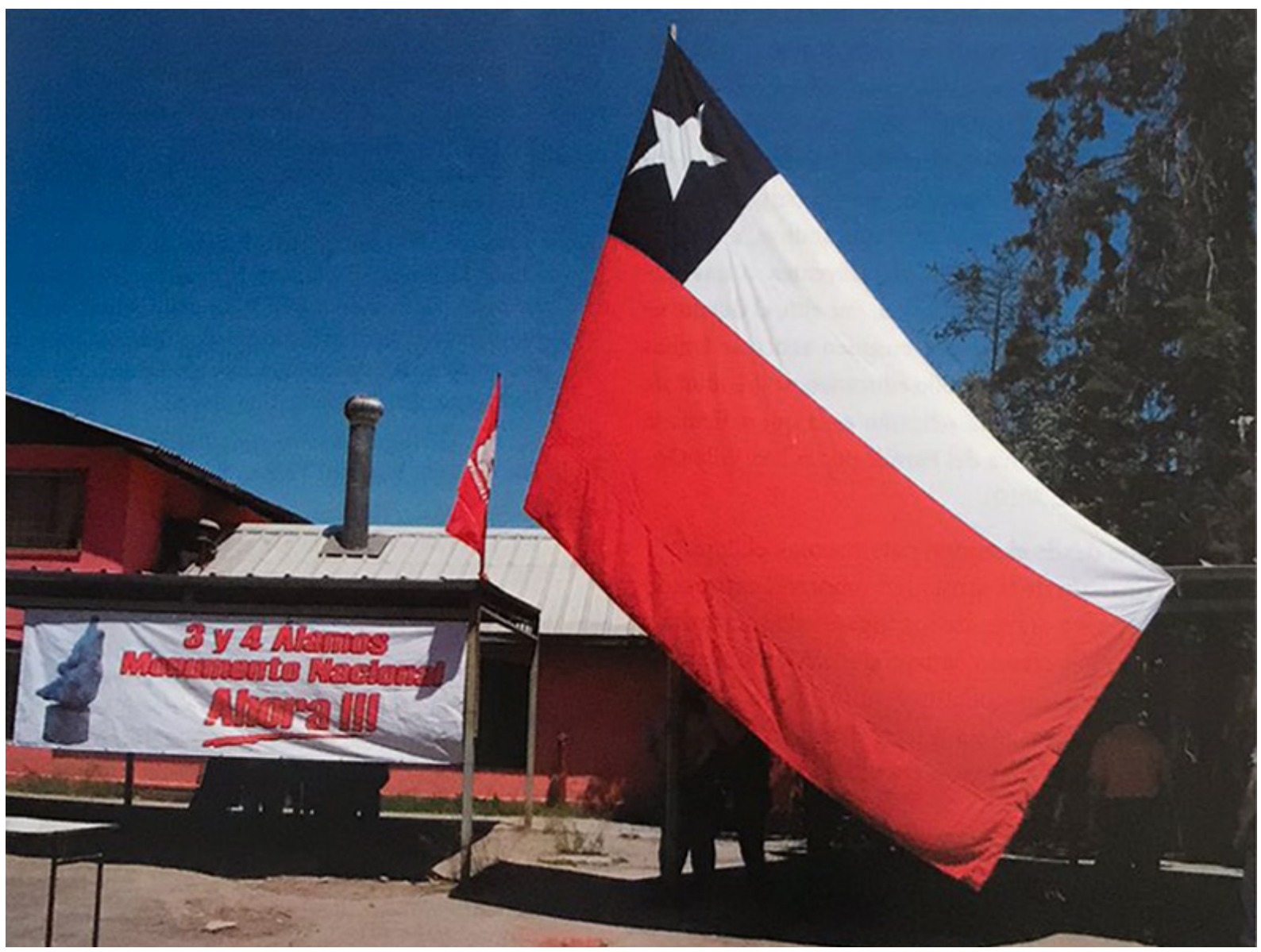


Reparación simbólica: una de las funciones claves de los lugares de memoria como patrimonio de la atrocidad y que establece una diferencia significativamente con otros patrimonios es la función de colocar en el centro de su gestión el reconocimiento de las víctimas; esto es de las personas que han sufrido violación de sus derechos humanos.

Conmemorativa/Cultural: parte importante de las acciones realizadas en los lugares de memoria se refiere a actividades culturales que ponen el acento en torno a la promoción de una cultura de los derechos humanos. Así también las actividades conmemorativas se relacionan con la puesta en valor de los hitos temporales como formas de recuerdo de los sucesos referidos al sitio.

Educativa: esta acción constituye un ejercicio clave de los lugares de memoria. Como se ha mencionado, la posibilidad de articular pasado con presente como un deber social se debe desarrollar en el marco de una propuesta de intervención que fomente la reflexión y el pensamiento crítico. Implementar una propuesta que articule la "Pedagogía de la Memoria" y la "Educación en Derechos Humanos" puede constituir la base fundamental de una propuesta educativa diferenciadora de un sitio de memoria, con respecto a otros espacios de educación no formal. Tanto la "Educación en Derechos Humanos" como la "Pedagogía de la Memoria" constituyen propuestas educativas que perfectamente pueden ser complementadas; sin embargo, muchas veces en la práctica tienden a confundirse, e incluso a veces se manifiestan como excluyentes, o una termina superponiéndose a la otra. Por ello, el desafío es concretizar propuestas que busquen articular ambas estrategias para el desarrollo educativo de los sitios de memoria. Parte de esta reflexión es la que articula la experiencia educativa del Parque por la Paz Villa Grimaldi. (Alegría, 2010)

Sin duda que desde el campo patrimonial, el denominado patrimonio de la atrocidad $\mathrm{u}$ horror, expresado en nuestro país a través de los lugares de memoria e incluso el recién creado Museo de la Memoria y los Derechos Humanos constituye uno de los desafíos claves sobre la relevancia que el discurso y práctica del patrimonio posee y poseerá en el siglo XXI.

\section{Bibliografía}

Alegría, L. (2010). Pedagogía de la Memoria y Educación en Derechos Humanos. Un modelo para armar, en Trabajos Educativos (1) Pedagogía de la Memoria Y Educación en Derechos Humanos. Santiago de Chile: Área Educación de la Corporación Parque Por La Paz Villa Grimaldi.

Ashworth, G. \& Hartman, R. (Eds.) (2005). Horror and Human Tragedy Revisited: The management of sites of atrocities for tourism. Nueva York: Cognizant Communication.

Burrin, P. (2004). Resentimiento y apocalipsis. Ensayo sobre el antisemitismo nazi. Madrid: Editorial Katz.

Déotte, J.L. (1998). Catástrofe y Olvido. Las ruinas, Europa, el Museo. Santiago: Editorial Cuarto Propio.

Faulenbach, B. (2010). La cultura de la memoria en Alemania. En Birle, P., Carnovale, V., Gruglewski, E. \& Shindel, E. (Eds.), Memorias urbanas en diálogo: Berlin y Buenos Aires (pp. 41-52). Buenos Aires: Editorial Buenos Libros.

Fernández, R. \& Piper, I. (2011). Lugares de memoria: usos, identidades y políticas en el Chile de hoy. En Vives, V. (Ed.) Cuaderno de Trabajo volumen 1, Memorias, Historia y Derechos Humanos. Santiago: Programa Domeyko, Universidad de Chile.

Forges, J.F. (2006). Educar contra Auschwitz. Historia y memoria. Buenos Aires: Editorial Antrophos.

García Canclini, N. (1993). Los usos sociales del Patrimonio. En Florescano, E. (Ed.) El Patrimonio Cultural de México. Buenos Aires: Editorial Fondo de Cultura Económico.

García Canclini, N. (2005). Definiciones en transición. En Mato, D. Cultura, política y sociedad Perspectivas latinoamericanas (pp. 69-81). Buenos Aires: CLACSO, Consejo Latinoamericano de Ciencias Sociales. Recuperado de http://bibliotecavirtual.clacso.org.ar/ar/ libros/grupos/mato/GarciaCanclini.rtf

Hernández, F. (2006). Planteamientos Teóricos de la Museología. Gijón: Editorial TREA.

Huyssen, A. (2002). En busca del futuro perdido. Cultura y memoria en tiempos de globalización. México: Editorial Fondo de Cultura Económica, México.

ICOM. (2010-2012). ICMEMO - Museos en memoria de víctimas de crímenes públicos. Comité internacional para museos en memoria de víctimas de crímenes públicos. Recuperado de http://icom.museum/los-comites/ comites-internacionales/comites-internacionales/comite-internacional-para-museos-en-memoria-de-victimas-de-crimenes-publicos/L/1/

Jelin, E. (Octubre, 2003). Los derechos humanos y la memoria de la violencia política y la represión: la construcción de un campo nuevo en las ciencias sociales. Cuadernos del IDES (2). Instituto de Desarrollo Económico y Social. Recuperado de http://biblioteca.clacso.edu. 
ar/gsdl/collect/ar/ar-025/index/assoc/HASH0104.dir/ cuad2.html

López, L., (2009). De los ex centros de detención a lugares de memoria del terrorismo de Estado, Revista Praxis, (15), pp. 131-140.

Marsal, D. (Noviembre, 2010).Patrimonio de la atrocidad: musealización del horror. Simposio llevado a cabo en el Seminario de Patrimonio Cultural en Chile, Santiago, Chile.

Nora, P. (2009). Los Lugares de memoria. Santiago: Editorial LOM.

Peris, J. (2005). La imposible Voz. Memoria y representación de los campos de concentración en Chile: la posición del testigo. Santiago: Editorial Cuarto Propio.

Prats, LL. (2005). Concepto y gestión del patrimonio local. Cuadernos de Antropología Social (21), 17-35.

Real Academia Española. (2014a) Diccionario de la Real Academia de la Lengua Española: horror. Recuperado de $\mathrm{http} / / / \mathrm{lema} . \mathrm{rae} . \mathrm{es} / \mathrm{drae} /$ ?val=HORROR

Real Academia Española. (2014b) Diccionario de la Real Academia de la Lengua Española: atrocidad. Recuperado de http://lema.rae.es/drae/?val=atrocidad

Richard, N. (2010). Crítica de la Memoria (1990-2010). Santiago: Ediciones Universidad Diego Portales.

Salvat, P. (2005). Derechos Humanos. En Salas, R. Pensamiento Crítico Latinoamericano. Conceptos fundamentales. Santiago: Editorial Universidad Católica Silva Henríquez.

Santacana, J. \& Hernández, F. (2006). Museología Crítica, Gijón: Editorial Trea.
Schaulsohn, B. (2000).Administración de justicia y Corte Penal Internacional. En Fernández, A., Hacia una cultura de los derechos humanos. Un Manual alternativo. Ginebra: Universidad de Verano de derechos Humanos y del Derecho a la Educación.

Silva, M. \& Rojas, M. (Noviembre, 2005). Sufrimiento y desapariciones: el manejo urbano arquitectónico de la memoria urbana traumatizada. Simposio llevado a cabo en el VII Seminario de Patrimonio Cultural: Territorios en Conflicto, DIBAM, Santiago, Chile.

UNESCO. (1993). Museum Internacional. Museos de la guerra y la paz, (XLV), 1. Recuperado de http://unesdoc. unesco.org/images/0009/000942/094281so.pdf

Vasconcellos, C. (2013). Patrimonio, memoria y educación: una visión museológica. Memoria y Sociedad. 17 (35), 94-105. Recuperado de http://webcache.googleusercontent.com/search?q=cache:http://www.scielo.org. co/pdf/meso/v17n35/v17n35a06.pdf

Venero, D. \& Toledo, M. (2009). Del uso pedagógico de lugares de memoria: visita de estudiantes de educación media al Parque por la Paz Villa Grimaldi. EStudios Pedagógicos $X X X V$, (35) 1, pp. 199- 220. Recuperado de http://www.scielo.cl/scielo.php?pi$\mathrm{d}=$ S0718-07052009000100012\&script=sci_arttext

Wilkanowicz, E. (1993). Auschwitz: el más extraño de los museos. UNESCO. Museum Internacional. Museos de la guerra y la paz, (XLV), 1, pp. 32-36. Recuperado de http://unesdoc.unesco.org/images/0009/000942/ 094281so.pdf 